\title{
Direct Measurement of Heat of Gasification for Polymethylmethacrylate
}

\author{
J. L. Jackson, Research Associate \\ Armstrong World Industries \\ Lancaster, PA 17604
}

U.S. DEPARTMENT OF COMMERCE

National Institute of Standards and Technology

(Formerly National Bureau of Standards

National Engineering Laboratory

Center for Fire Research

Gaithersburg, MD 20899

September 1986

Issued October 1988

National Bureau of Standards became the

National Institute of Standards and Technology

on August 23, 1988, when the Omnibus Trade and

Competitiveness Act was signed. NIST retains

all NBS functions. Its new programs will encourage

improved use of technology by U.S. industry.

\section{U.S. DEPARTMENT OF COMMERCE}

C. William Verity, Secretary

\author{
NATIONAL INSTITUTE OF STANDARDS \\ AND TECHNOLOGY \\ Ernest Ambler, Director
}





\title{
NISTIR 88-3809
}

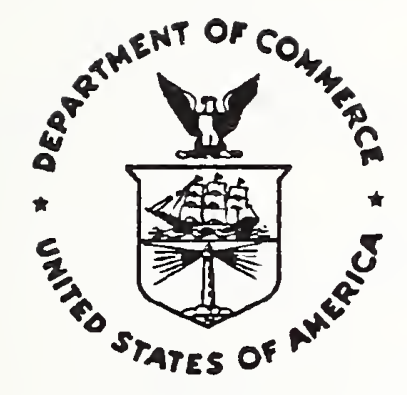

\section{Direct Measurement of Heat of Gasification for Polymethylmethacrylate}

\author{
J. L. Jackson, Research Associate \\ Armstrong World Industries \\ Lancaster, PA 17604
}

U.S. DEPARTMENT OF COMMERCE

National Institute of Standards and Technology

(Formerly National Bureau of Standards

National Engineering Laboratory

Center for Fire Research

Gaithersburg, MD 20899

September 1986

Issued October 1988

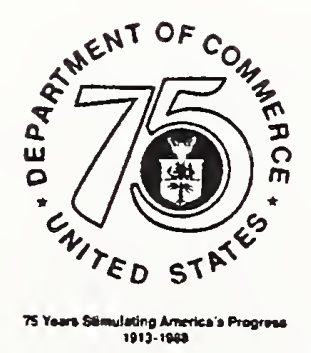





\section{Page}

LIST OF TABLES

LIST OF FIGURES $\ldots \ldots \ldots \ldots \ldots \ldots \ldots \ldots \ldots \ldots \ldots \ldots \ldots \ldots \ldots$

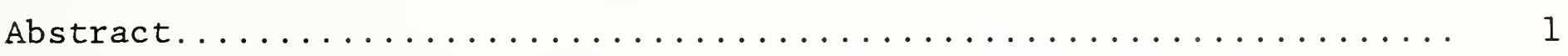

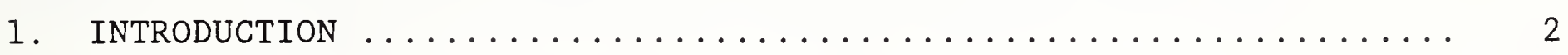

2. Background Theory .......................... 3

3. Experimental Technique and Procedures ................ 7

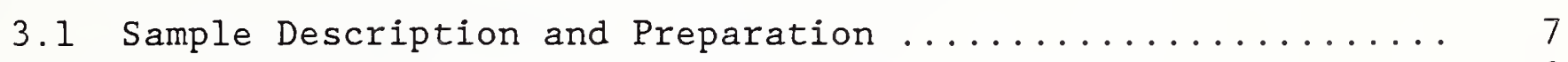

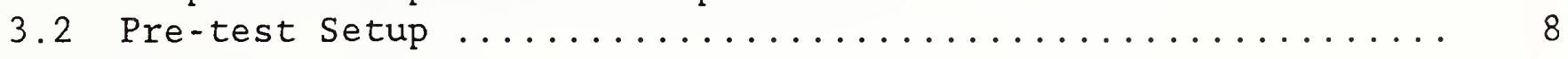

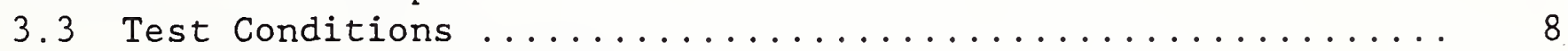

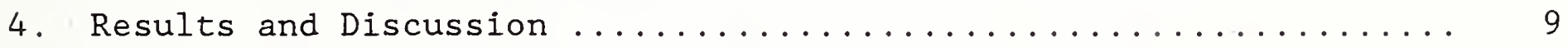

4.1 Apparatus Operation ....................... 9

4.2 Test Series Results ........................ 11

5. Recommendations .......................... 13

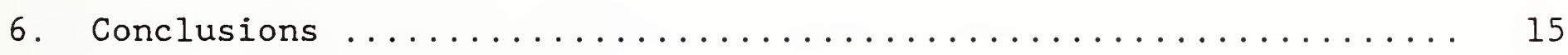

7. Acknowledgements .......................... 15

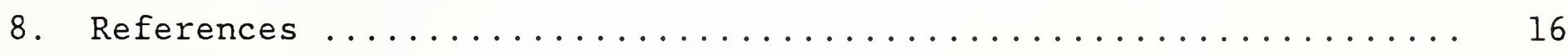

9. NOMENCLATURE ........................... 17

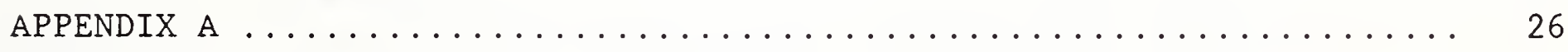


List of Tables

Page

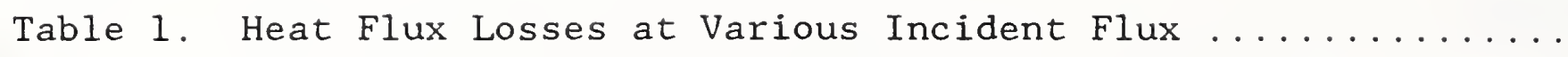


Figure 1. Schematic of heat of gasification apparatus ........ 18

Figure 2. Mass loss rate versus time at various incident

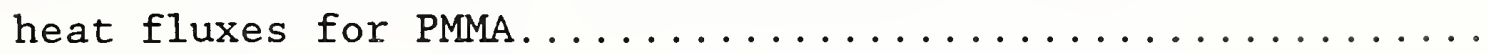

Figure 3. Peak rate of weight loss versus incident heat fluxes

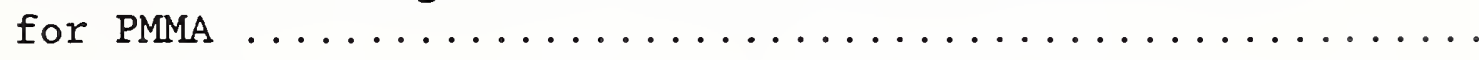

Figure 4. Top surface temperature versus time at various

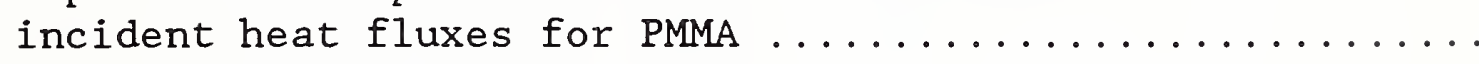

Figure 5. Bottom surface temperature versus time at various

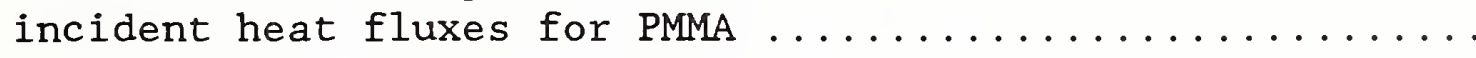

Figure 6. Absorbed heat versus time at various incident

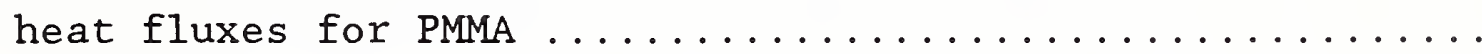

Figure 7. Heat of gasification versus time at various

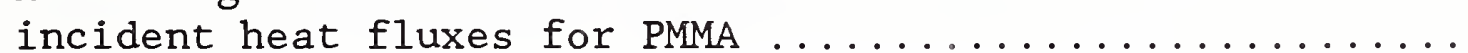

Figure 8. Asymptotic heat of gasification versus incident

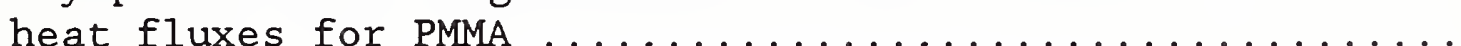

Figure A-1. Top Surface Temperature Versus Time at Various

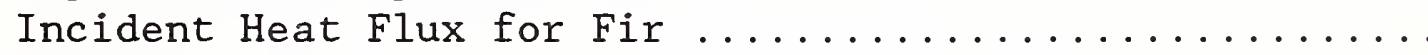

Figure A-2. Top Surface Temperature Versus Time of Various

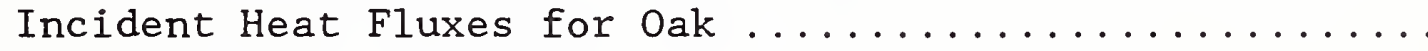

Figure A-3. Mass Loss Rate Versus Time at Various Heat Fluxes

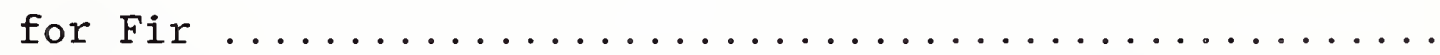

Figure A-4. Mass Loss Rate Versus Time at Various Heat Fluxes

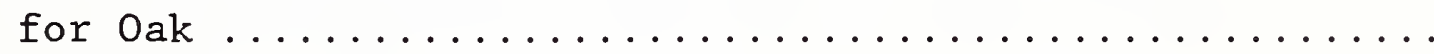

Figure A-5. Peak Rate of Weight Loss Versus Incident Heat Flux

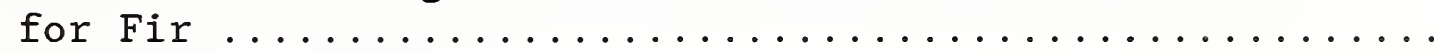

Figure A-6. Peak Rate of Weight Loss Versus Incident Heat Flux

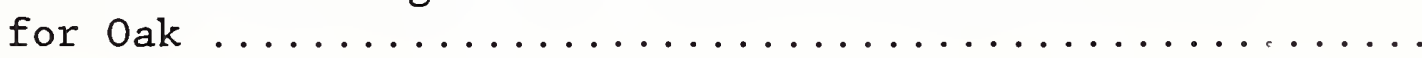





\section{DIRECT MEASUREMENT OF HEAT OF GASIFICATION FOR POLYMETHYLMETHACRYLATE}

J. L. Jackson

\section{Abstract}

A laboratory scale apparatus has been developed for the direct measurement of the heat of gasification for solid fuels. The apparatus has been designed to simulate radiant energy transfer rates found under actual fire conditions and designed in such a way that the energy gains and losses with respect to the sample surfaces are well defined. Calculation of the time dependent heat of gasification for solid fuels relies on the ability to measure accurately and continuously the time dependent energy transfer rates and material responses. Tests have been conducted in which samples of polymethylmethacrylate were subjected to incident heat fluxes ranging from 1 to $4 \mathrm{~W} / \mathrm{cm}^{2}$. Test results indicate that under these conditions the heat of gasification is significantly influenced by the time dependent thermal properties of the material and approaches an asymptotic value that varies with incident heat flux. The asymptotic values decrease with increasing incident heat flux and approach a value of $1600 \mathrm{~J} / \mathrm{g}$ which is consistent with values published by other investigators. Refinement of the apparatus and the testing of other materials is continuing. Results for two additional materials, fir and oak are included as Appendix A.

Key words: burning rate; charring materials; gasification; and polymethylmethacrylate; pyrolysis; solid fuels; thermals properties. 


\section{INTRODUCTION}

One of the continuing concerns and desires of the fire research community is the development of the ability to predict accurately the burning rates of solid fuels. To develop the modeling tools necessary to do this, much information is needed regarding the fundamental properties of materials and their relationship to material responses under fire conditions. In some cases the complexities of modeling such properties can be reduced by studying and modeling the overall effect of several processes. The study of heat of gasification is an example of such an approach which involves characterization of the combined energetic effects of all of the chemical processes that produce fuel gases from the original solid material. The heat of gasification is therefore defined for this study as the net amount of absorbed energy required to gasify a unit mass of given material.

The measurement of heat of gasification has previously been performed using various indirect methods. The most recent of these methods was developed by Tewarson[1-3]. This method involves continuous measurement of the mass loss of the test sample for various incident heat fluxes. The peak mass loss rate is then plotted as a function of incident heat flux. For polymethylmethacrylate (PMMA) and various other materials this plotted data suggests a linear relationship between the peak mass loss rate and the incident heat flux. The slope of the linear solution derived from a least squares analysis of the data is equal to the inverse of the heat of gasification. Values for heat of gasification determined using this method are consistent with values determined by thermal gravimetric analysis and other techniques. This 
analysis method however is limited to the use of data which represents steady state conditions.

Materials receiving external incident flux from the flames of a developing fire undergo a non-steady state thermal energy transfer. Under these conditions the instantaneous value of the mass loss rate and the net amount of heat absorbed by the sample will vary as a function of time. This would then imply that the instantaneous value of the heat of gasification will also vary as a function of time. The impetus for the work presented in this paper is to measure this time dependent behavior. The objective of the work has been the development and construction of a laboratory scale apparatus for the direct measurement of quantities used to calculate the heat of gasification. The apparatus has been designed to simulate thermal energy transfer under fire conditions and designed in such a way that the energy gains and losses with respect to the sample surfaces are well defined and continuously measurable. The net energy absorbed by the test sample is the difference between the energy gained and lost at any time. The mass loss rate can be determined from the continuous measurement of the sample mass. The heat of gasification at any given time is then calculated by dividing the net absorbed heat flux by the mass loss rate at that time. Descriptions of the apparatus, experimental procedures, analysis approach and test results are included in this paper.

\section{BACKGROUND THEORY}

The definition of heat of gasification for this study is: 


$$
L_{g}=\frac{q_{\text {net }}^{\prime \prime}}{\dot{m} "}
$$

where $\mathrm{Lg}$ is the heat of gasification, $\dot{q} "_{n \text { et }}$ represents the net absorbed heat flux and $\dot{m}^{\prime \prime}$ is the mass loss rate per unit area (Section 9. Nomenclature).

The net energy absorbed by the test sample can be calculated from the energy balance equation, Eq. (2), which describes the energy transfer into and out of the sample material.

$$
\dot{q}{ }_{n e t}=\dot{q}{ }_{i n c}-\dot{q} "_{r r}-\dot{q} "_{r e f}-\dot{q} n_{c v}-\dot{q}{ }_{c d}
$$

Equation (2) is applicable to a configuration where the top surface of the sample is exposed to an incident radiant flux while the side and bottom surfaces are thermally insulated. To be able to directly measure the heat of gasification as a function of time, the time dependent terms in Eq. (2), as well as the time dependent mass loss rate must be continuously measured. Figure 1 schematically shows the apparatus which has been designed to obtain these measurements.

The incident flux is provided by a conical shaped black body radiant heater comprised of a $6^{3 / 2}$ turn Incoloy electrical heating element. This heater provides a uniform heat flux $4 \mathrm{~cm}$ below the $16 \mathrm{~cm}$ diameter base of the heater with at most a 3:5 percent deviation from the average flux. The -incident flux from the heater is adjusted prior to each test based on measurements made with 
a total heat flux gage placed in the position occupied by the test sample during actual testing. The top of the heater assembly has an orifice through which a radiometer positioned above it can measure the combined re-radiated and reflected heat flux from the top surface of the sample. The heater assembly is positioned on top of a rectangular shaped conduit which serves as a pyrolysis chamber. The vertical movement of the pyrolysis chamber is independent of the sample cup and load cell system. This allows the chamber to be repositioned during tests to keep the regressing top surface of the sample in the uniform flux area $4 \mathrm{~cm}$ below the heater.

The side and bottom surfaces of the test sample are thermally insulated using a low density ceramic fiber material. From the thermal conductivity of the insulation material and the measurement of the differential temperature across the insulation thickness, the energy being conducted away from the side and bottom surfaces is calculated assuming steady state conditions from Eq. (3). More detailed transient calculations were not used because the conductive heat loss is expected to be small.

$$
\dot{q}_{c d}=\frac{k_{i}\left[T_{b}-T_{c b}\right]}{h_{b}}+\frac{k_{i}\left[T_{s}-T_{c s}\right]}{h_{s}}
$$

A flow of nitrogen is introduced into one end of the pyrolysis chamber and passes through a porous metal plate to produce a uniform flow pattern which passes over the top surface of the test sample. Although the nitrogen flow produces the convective heat loss, it provides three critical functions. By exhausting much of the pyrolyzates through the end of the pyrolysis chamber, the nitrogen flow minimizes" the effects of the pyrolyzates gases above the fuel surface from attenuating the incident radiant heat flux from 
the heater [4] and from attenuating the re-radiated and reflected heat flux being measured by the radiometer. The nitrogen flow also purges the oxygen from the pyrolysis chamber and prevents the thermally initiated process from being influenced by the presence of oxygen [5]. Finally, with reduced oxygen present in the pyrolysis chamber ignition of the combustible pyrolyzates is prevented. Measurement of the upstream velocity and temperature of the nitrogen flow, and the temperature of the top surface of the test sample permits the convected heat loss $\left(\dot{q}_{c v}\right)$ to be calculated from Eq. (4) which is the convective heat transfer coefficient for flat plate boundary layer flow without surface mass injection [6], the geometry of the sample and pyrolysis chamber and the sample surface to nitrogen gas flow temperature difference as:

$\dot{q}_{c v}=\int_{x=x_{0}}^{x_{1}}\left(r^{2}-\left(\left(x_{1}+x_{0}\right) / 2-x\right)^{2}\right)^{1 / 2}(0.332) k \operatorname{Pr}^{1 / 3}\left(\frac{u_{\infty}}{v x}\right)^{1 / 2}\left(1-\left(\frac{x_{0}}{x}\right)^{3 / 4}\right)^{-1 / 3} \Delta T_{(x)} d x$

The mass of the test sample is continuously measured using a load cell system. During the initial stage of sample testing the mass of the test sample is constant, the mass loss rate is zero, and therefore, from Eq. (2), the instantaneous value of the heat of gasification is infinite. The value then decreases as gasification and weight loss begins. In this study, a multiple regression analysis is used to produce the coefficients for a third order polynomial which expresses the sample mass as a function of time for the time period after gasification and mass loss have been established. The first derivative with respect to time of the polynomial expression then gives the mass loss rate of the sample as a function of time. 


\section{EXPERIMENTAL TECHNIQUE AND PROCEDURES}

\subsection{Sample Description and Preparation}

Samples of PMMA (Rohm and Hass Plexiglass Type G) ${ }^{1}$ were tested. Test sample dimensions were $2.5 \mathrm{~cm}$ thick and $9.0 \mathrm{~cm}$ in diameter. A type $\mathrm{K}$ thermocouple $(0.00787 \mathrm{~cm}$ dia.) is thermally embedded in the top surface of the test sample. The clip leads used to connect the thermocouple to the data acquisition system are of sufficient weight to maintain the contact between the thermocouple and the test sample while the sample surface regresses during the test. The side and bottom surfaces were covered with aluminum foil leaving the top surface and $1.0 \mathrm{~cm}$ of the side surface exposed. Low density ceramic fiber insulation $(3.5 \mathrm{~cm}$ thickness on the bottom, 0.8 thickness $\mathrm{cm}$ on the side) is used in the sample cup to minimize the conductive heat loss from the side and bottom surfaces. Type $\mathrm{K}$ thermocouples are positioned on both sides of the insulation for measurement of the temperature differential across the insulation.

Results from supplemental tests ${ }^{2}$ on two charring materials, fir and oak, are included in the Appendix.

${ }^{1}$ Product identification has been used here to provide an accurate description of the material tested. The use of this product name does not constitute an endorsement by the National Bureau of Standards.

.... 2 These tests were conducted by NBS Guest Worker, Mr. Ji-Jen, Chiou of the Chung Shan Institute of Science and Technology, Taiwan. 
The Gardon ${ }^{3}$ type radiometer is positioned $31 \mathrm{~cm}$ above the test sample surface. Using a 7 degree view angle restrictor, approximately 90 percent of the top surface of the test sample can be viewed. Water, held constant at room temperature and flowing at a rate of $26 \mathrm{~cm}^{3} / \mathrm{s}$, is used to cool the radiometer and the view restrictor. The nitrogen flow rate for these test ranged from 2400 to $3200 \mathrm{~cm}^{3} / \mathrm{s}$ through the $4 \mathrm{~cm}$ by $20 \mathrm{~cm}$ by $35 \mathrm{~cm}$ pyrolysis chamber. The incident heat flux from the radiant heater was measured with a Gardon type total heat flux gage positioned in the location of the test sample. After setting the heater for the desired incident heat flux the system is allowed to come to equilibrium over a period of one hour. A shutter. in the bottom of the pyrolysis chamber prevents the sample from being exposed to the incident heat flux until the test begins. After equilibrium has been reached, zero settings for the radiometer and load cell are established.

\subsection{Test Conditions}

The PMMA samples were tested at incident heat fluxes ranging from 1 to $4 \mathrm{~W} / \mathrm{cm}^{2}$, simulating the thermal radiation from the flames of a developing fire. Data from all transducers was recorded every three seconds and then analyzed at the end of the test using a computer based data acquisition system. Tests at incident heat fluxes less than or equal to $2 \mathrm{~W} / \mathrm{cm}^{2}$ were terminated at an elapsed time of 60 minutes. Tests at incident heat fluxes

a... "Gardon type"-refers to transducers which provide an electrical signal directly proportional to the thermal energy absorbed by its heat-sensitive surface. 
greater than $2 \mathrm{~W} / \mathrm{cm}^{2}$ were terminated when the surface regression could no longer be followed by manually repositioning the pyrolysis chamber and the surface regressed below the bottom of the pyrolysis chamber. At this point approximately 60 percent of the sample has been pyrolized. Generally, two samples were tested at each incident heat flux.

\section{RESULTS AND DISCUSSION \\ 4.1 Apparatus Operation}

A total heat flux gage placed in the position of the test sample is used to measure the incident heat flux from the heater. Once equilibrium has been established for a specific test, the temperature of the heating element is noted. To maintain a constant heat flux, the voltage to the heating element. is manually adjusted to keep the heating element at the noted temperature. With this method of operation the variance in the incident heat flux cculd be held to within $+/-0.01 \mathrm{~W} / \mathrm{cm}^{2}$ of the initial setting. Tests were conducted to determine the uniformity of the incident heat flux from the conical shaped heater. These tests showed that in the sample area $4 \mathrm{~cm}$ below the heater the maximum percent deviation from the average heat flux was 3.5 percent.

To overcome the buoyancy driven flow caused by the incident heat flux, it was necessary to use flow rates of from 2400 to $3200 \mathrm{~cm}^{3} / \mathrm{s}$ for the nitrogen flow to flush fuel products through the side of the chamber. To maintain these flow rates for long periods of time for tests at the lower incident heat flux required the use of a large capacity liquid nitrogen tank as the source. Tests with an oxygen analyzer revealed that no oxygen was present at the 
leading edge of the sample; however, oxygen was detected at the trailing edge in concentrations of 1 to 4 percent.

The pyrolysis chamber and the sample cup/load cell assembly were designed as separate components. This allows the pyrolysis chamber to be lowered over the sample and allows the chamber position to be continuously adjusted to maintain the $4 \mathrm{~cm}$ distance between the regressing top surface of the sample and the bottom of the top surface for a distance of approximately $1.5 \mathrm{~cm}$. Attempts to go further would result in the chamber resting on the sample cup causing erroneous weight measurements.

Due to the sensitivity of the radiometer, it was necessary to thermally insulate the radiometer, the view restrictor and the tubing for the cooling water. This was done to minimize the shift in the zero flux reading caused by small changes in the temperature of the body of the radiometer. It was then necessary to establish a zero reading after the system had come to equilibrium, just prior to exposing the sample to the incident flux.

For the two charring materials, it was necessary to modify the apparatus to ensure that the radiative measurement were only the results from the specimen degradation, i.e., that oxidation did not produce a secondary heat source from the burning specimen. These modifications included reducing the area enclosing the sample cup holder to $0.5 \mathrm{~cm}^{2}$ and restricting the length of the opening for the pyrolysis products exhaust duct to $6.0 \mathrm{~cm}$. 


\subsection{Test Series Results}

The results of the test series in which samples of PMMA were tested at incident heat flux ranging from 1 to $4 \mathrm{~W} / \mathrm{cm}^{2}$ are shown in Figures $2-8$. These results indicate that under these conditions the heat of gasification, as defined in Eq. (1), is significantly influenced by the time dependent thermal properties of the material.

The results the test series in which samples of two charring materials, fir and oak, were tested at incident heat flux ranges from 1 to $4 \mathrm{~W} / \mathrm{cm}^{2}$ are shown in Figures Al-A6.

The physical meaning of the peaks in the mass.loss rate versus time curves in Figure 2 is unclear from this data. There are several parameters which appear to influence the peak mass loss rate values including the time dependent size of the pyrolysis zone, the thickness of the material, the thermal diffusivity of the material, the viscosity of the molten polymer, the surface regression rate, the particular mechanisms by which the material depolymerizes and degrades, as well as others. The peak mass loss rate versus incident heat flux data is shown in Figure 3. From a least squares analysis of this data, the inverse of the slope of the linear solution, i.e. the heat of gasification as defined by Tewarson [2], is equal to $1890 \mathrm{~J} / \mathrm{g}$.

The top surface temperature versus time data shown in Figure 4 indicates that the top surface reaches a steady state temperature in a short period of time, particularly at the higher incident heat flux. However, the bottom 
temperature versus time data in Figure 5 shows that the enthalpy of the system does not reach a steady state condition for the range of incident flux tested in this series.

The net heat flux absorbed by the sample as a function of time is shown in Figure 6. The data for the heat flux losses, used in equation 2 to calculate net heat flux absorbed by the sample, indicates that the predominant loss is due to re-radiation and reflection from the top surface. Data for the heat flux losses at peak mass loss rate for various incident heat fluxes is shown in Table 1 .

Table 1

Heat Flux Losses As a Function of Incident Heat

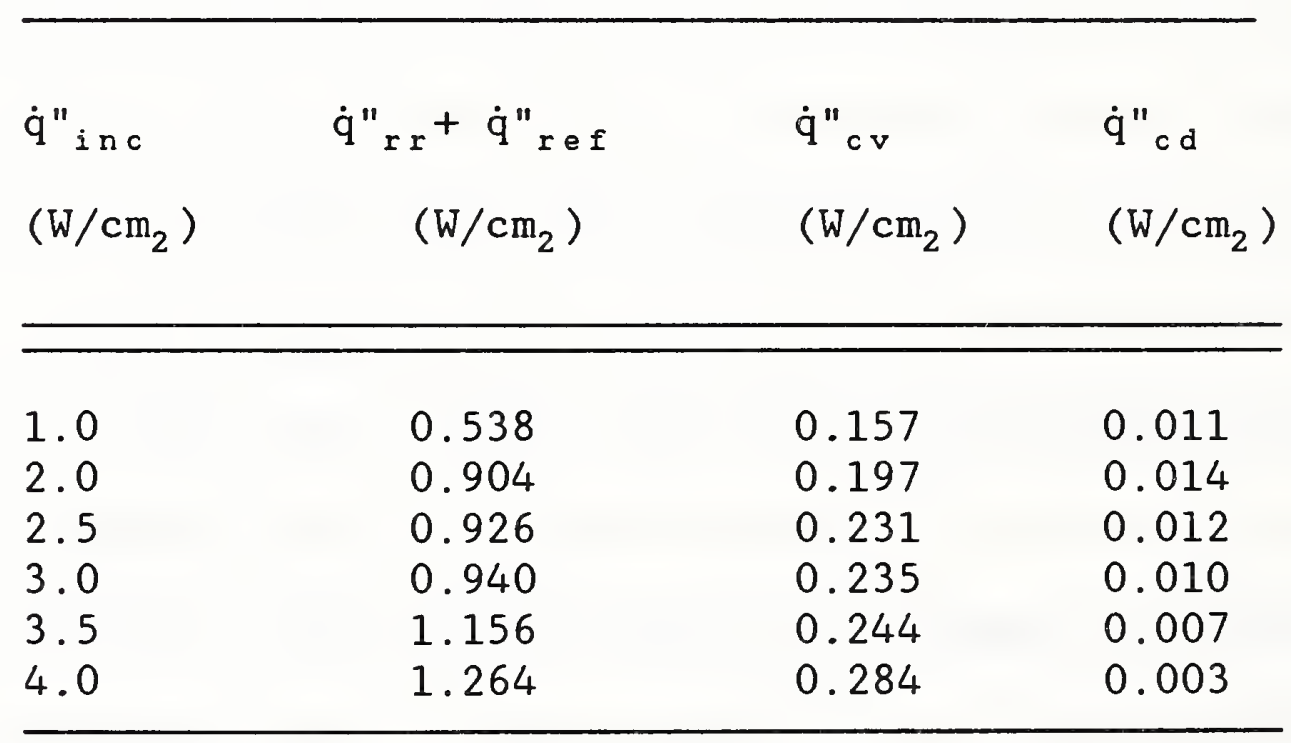

Figure 7 shows that the time dependent heat of gasification at each incident heat flux approaches an asymptotic value that varies with incident heat flux. As shown in Figure 8, these asymptotic values decrease with 
increasing incident heat flux and approach a value of $1600 \mathrm{~J} / \mathrm{g}$ which is consistent with values published by other investigators including Tewarson $[1,2]$ and Vovelle et al [3].

\section{RECOMMENDATIONS}

There are several areas in which improvements to the apparatus are needed. It is important to exhaust the pyrolyzates through the exhaust end of the chamber and not up through the heater orifice. It is also important that the oxygen in the chamber be completely purged. To achieve this the velocity of the nitrogen flow should be increased. It is desirable to increase the velocity of the nitrogen flow by modifying the size and/or configuration of the chamber as opposed to merely increasing the flow rate. The flow rates. used in this work are approaching prohibitive levels. The best results would be achieved if the flow rate could actually be reduced to $1600 \mathrm{~cm}^{3} / \mathrm{s}$ while increasing the velocity by 20 to 30 percent. Another modification which would aid in properly exhausting the pyrolyzates would require reducing the size of the orifice in the top of the heater assembly. This may also require adjusting the position of the radiometer.

It was observed that the nitrogen flow had a cooling effect on the apparatus when using the liquid nitrogen tank as the source. This then required continuously adjusting the heater control to compensate for the cooling effect and to maintain the incident heat flux. The recommended improvement would be to use a water bath to allow the nitrogen to reach room temperature before entering the pyrolysis chamber. 
Using a multiple regression analysis to curve fit the sample weight data to a third order polynomial produced excellent results. However, this then forces the first derivative, which is used to calculate the weight loss rate; to be a second order polynomial. Better results could be achieved if a higher order polynomial is used with the multiple regression analysis.

The equation used to calculate the convective heat loss, Eq. (4), was based on the theoretical determination of the convective heat transfer coefficient. The convective heat transfer is very complex for this apparatus. Better results for determining the convective heat loss would be achieved if the heat transfer coefficient-is determined experimentally.

The elapsed time of the test is limited by the ability to follow the regressing sample surface. The sample cup and the method of insulating the side and bottom surfaces of the sample require modifications that will allow the repositioning of the pyrolysis chamber, which maintains the relative distance between the heater and the regressing sample surface, to continue over longer surface regression distances. This will be especially desirable for testing samples of greater thickness.

\section{CONCLUSIONS}

The direct measurement of the heat of gasification using the apparatus developed in this work shows that in the range of incident heat flux tested 
the time dependency of the heat of gasification is significant. This implies that in this range the use of the constant value of heat of gasification, as determined by the methods of Tewarson and Vovelle et al, to predict mass loss rate for a given incident heat flux will result in values significantly greater than the measured values. Refinement of the apparatus and the testing of other materials is continuing.

\section{ACKNOWLEDGEMENTS}

The work presented in this paper was done in the laboratories of the Center for Fire Research at the National Bureau of Standards under their research associate program. The generous support from CFR and its staff was greatly appreciated. The author would also like to thank Mr: Ji-Jen Chiou of: the Chung Shan Institute of Science and Technology, Taiwan for his assistance during the PMMA experimentation phases and for his measurements for Fir and Oak included in the Appendix. 


\section{REFERENCES}

1. TEWARSON, A., " Experimental Evaluation of the Flammability Parameters of Polymeric Materials". Factory Mutual Research Corporation, Norwood, Massachusetts. Technical Report 1A6R1.RC (R79-T-9), February 1979.

2. TEWARSON, A., AND PION, R., "A Laboratory-Scale Test Method for the Measurement of Flammability Parameters", Factory Mutual Research Corporation, Norwood, Massachusetts, Technical Report 22424, (RC77-T-50), October 1977.

3. VOVELle, C., AKRICH, R., AND DELFAU J., "Mass Loss Rate Measurements on Solid Materials Under Radiative Heating", Combustion Science Technology, Vol. 36, 1(1984).

4. KASHIWAGI, T., "Radiative Ignition Mechanism of Solid Fuels", Fire Safety Journal, 3(1981)185-200.

5. KASHIWAGI, T., AND OHLEMILLER, T., "A Study of Oxygen Effects on Nonflaming Transient Gasification of PMMA and PE During Thermal Irradiation", Nineteenth Symposium on Combustion, The Combustion Institute, (1982)815-823.

6. HOLMAN, J., Heat Transfer, McGraw-Hill, New York, p. 191, 1981. 


\section{NOMENCLATURE}

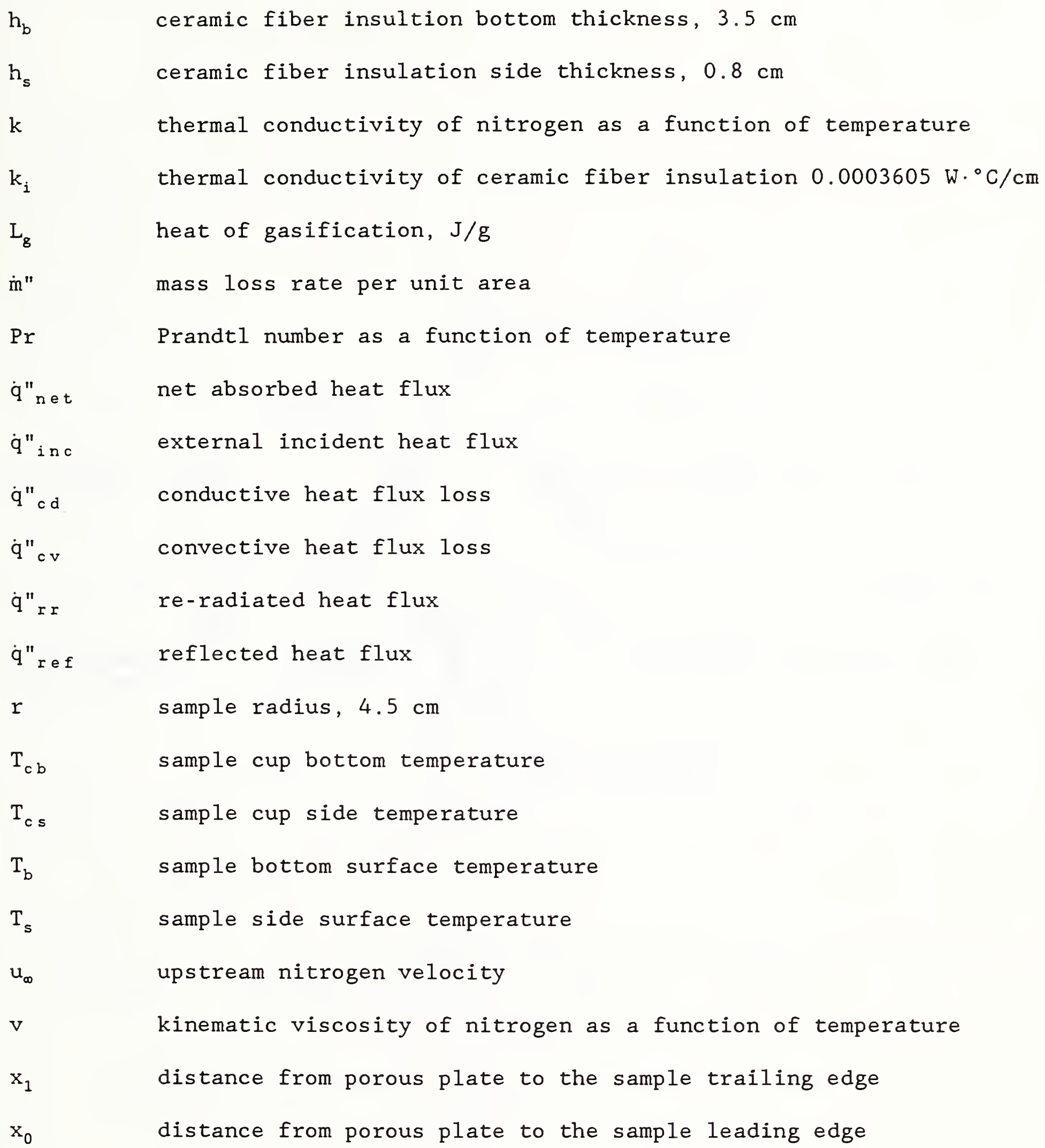




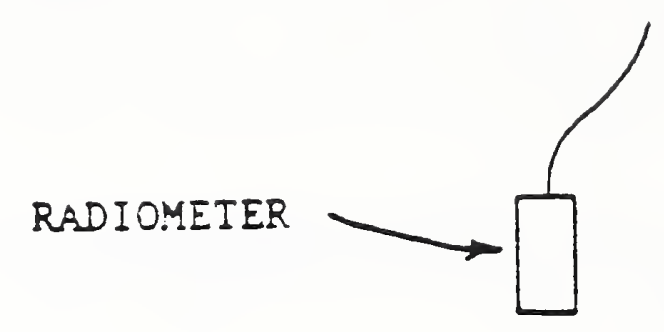

Heater Thermocouple

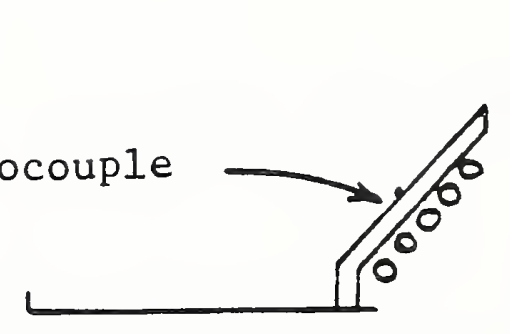

EXHAUSI

Sample Surface Thermocouple
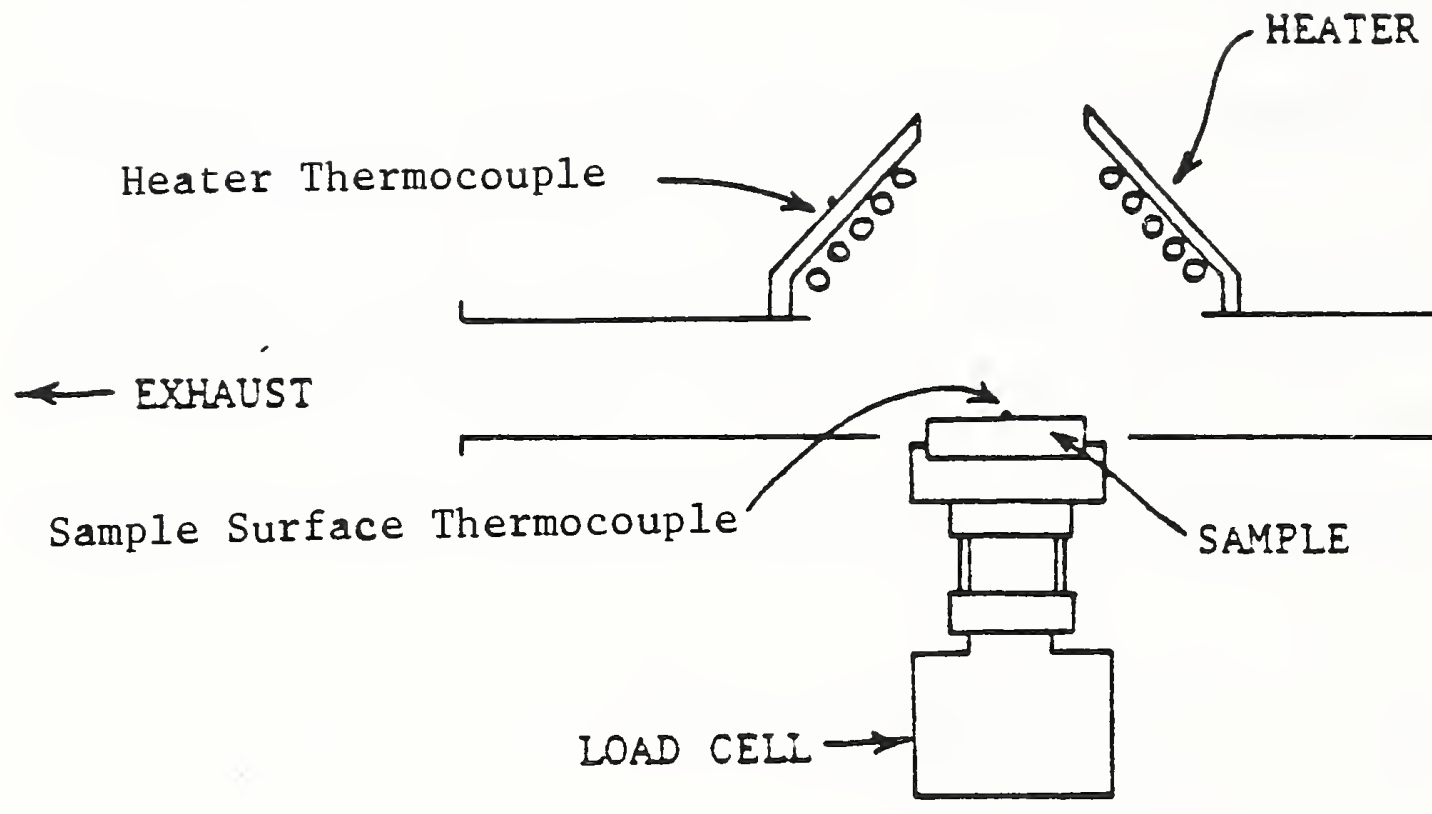

POROUS METAL PLAIE

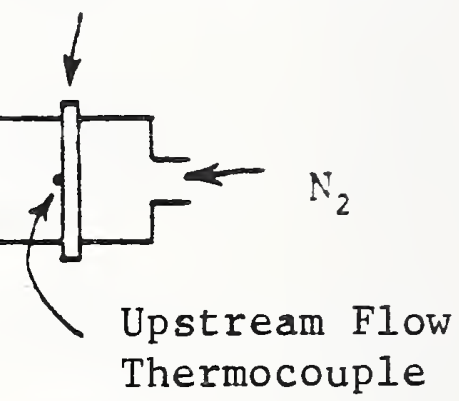

Figure 1. Schematic of heat of gasification apparatus 


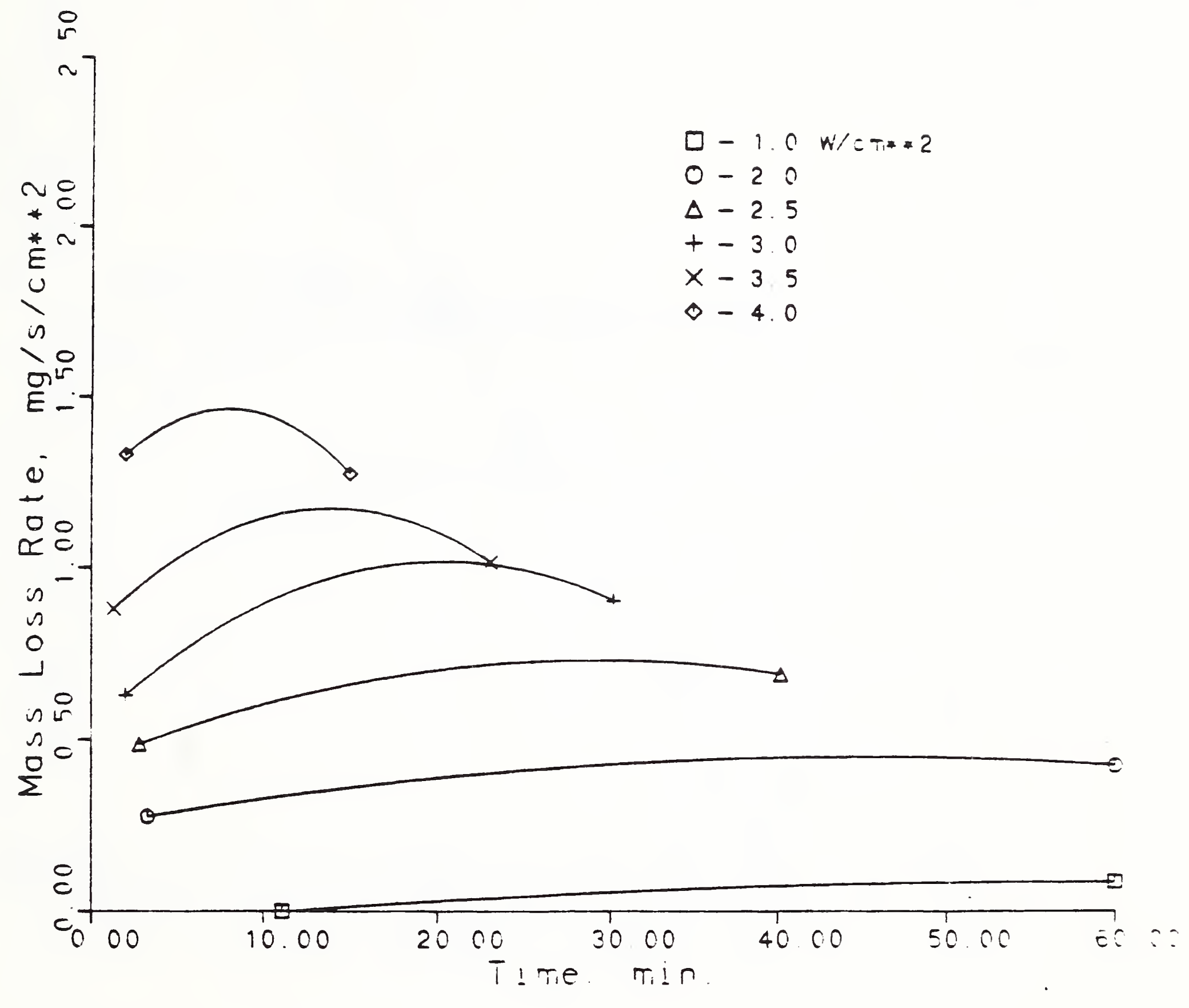

Figure 2. Mass loss rate versus time at various incident heat fluxes for PMMA. 


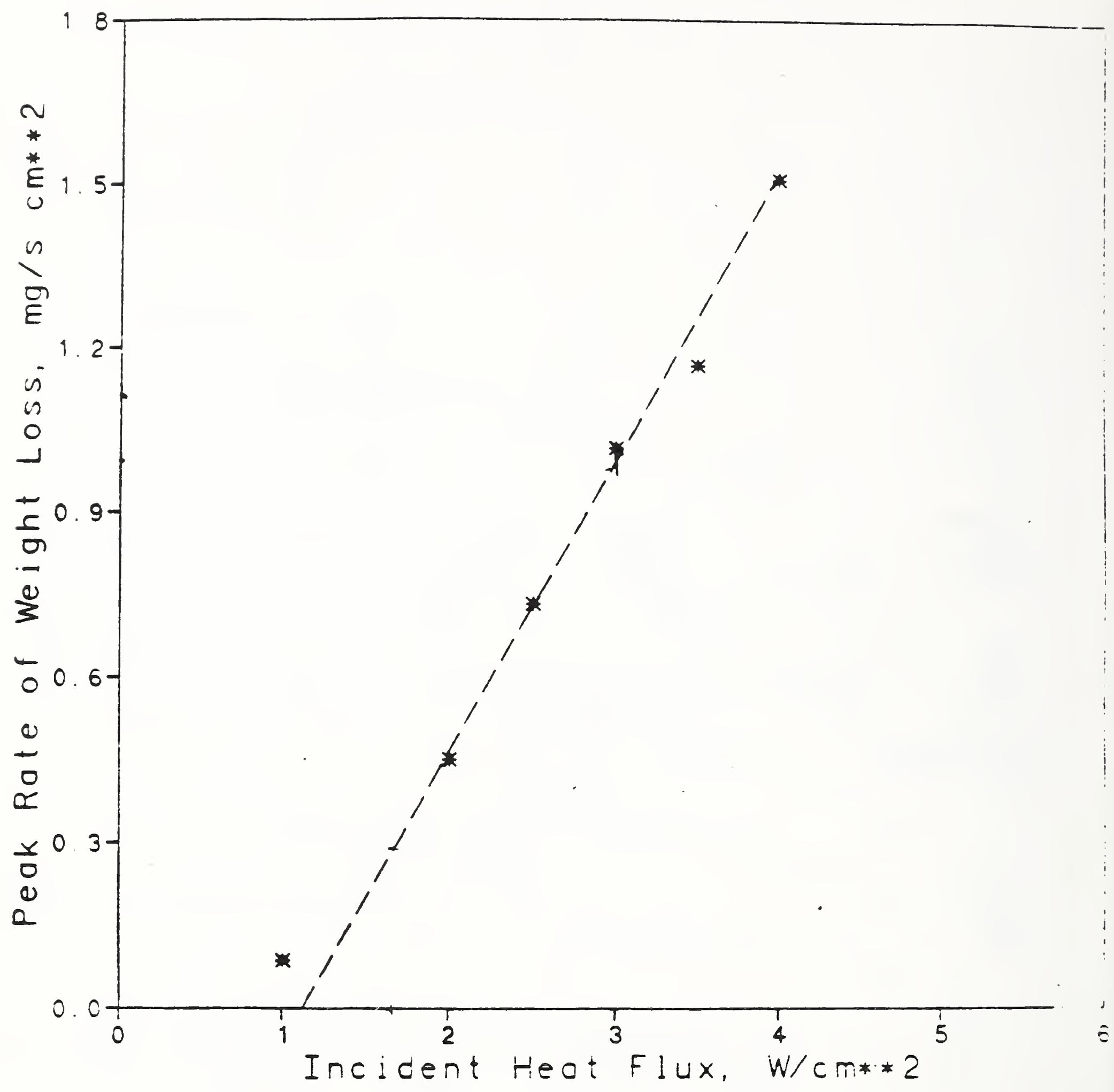

Figure 3. Peak rate of weight loss versus incident heat fluxes for PMMA. 


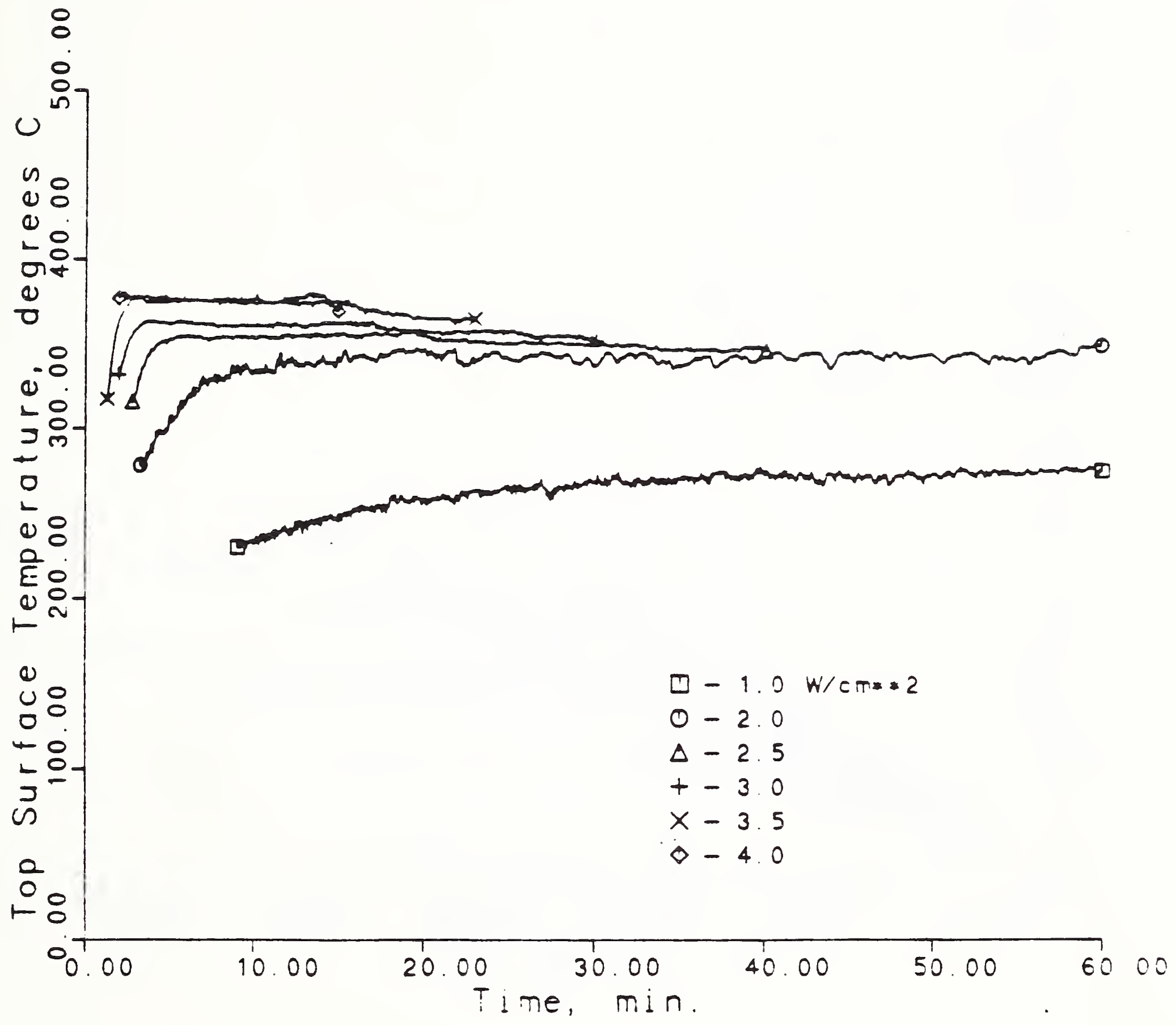

Figure 4. Top surface temperature versus time at various incident heat fluxes for PMMA. 


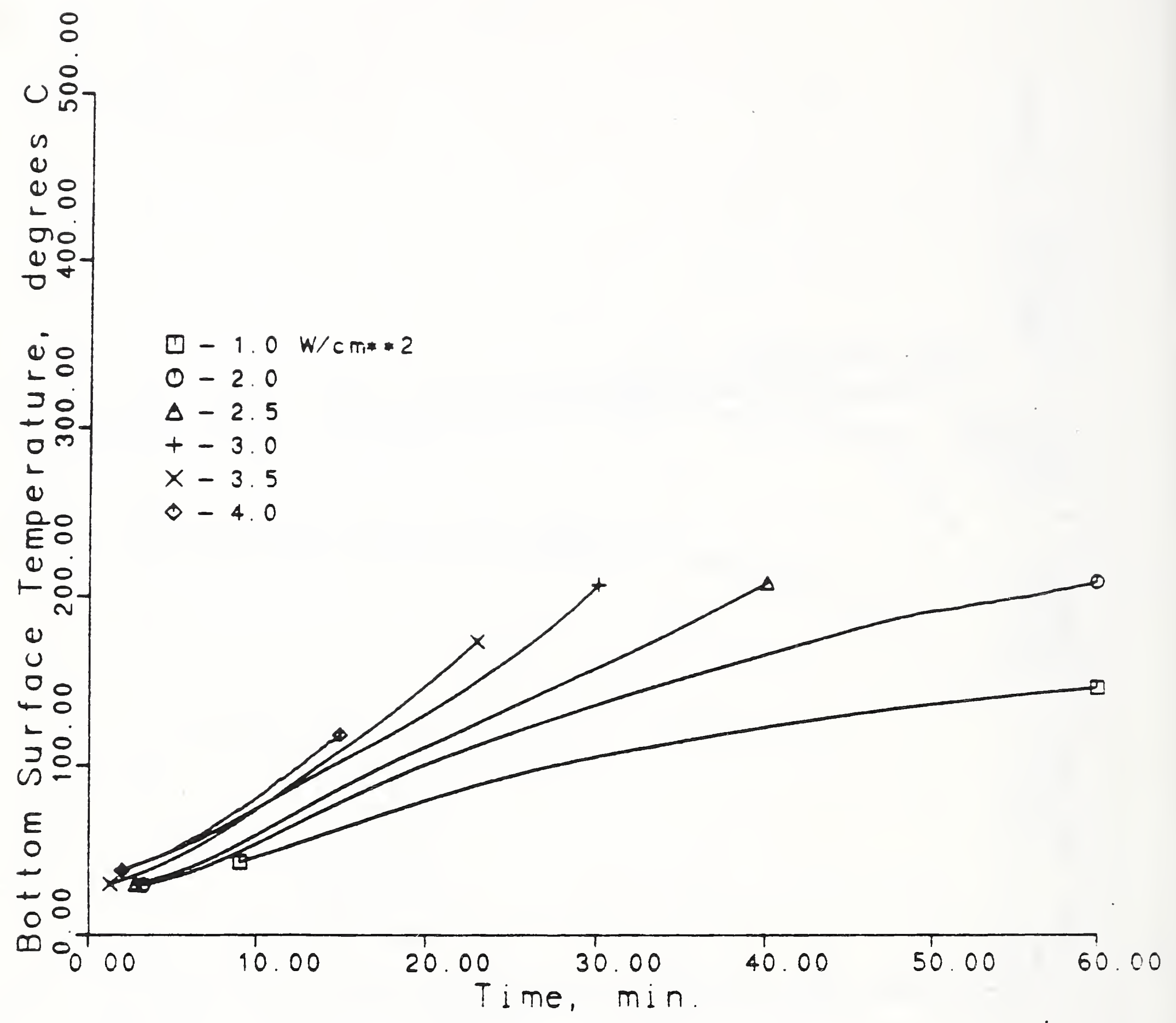

Figure 5. Bottom surface temperature versus time at various incident heat fluxes for PMMA. 


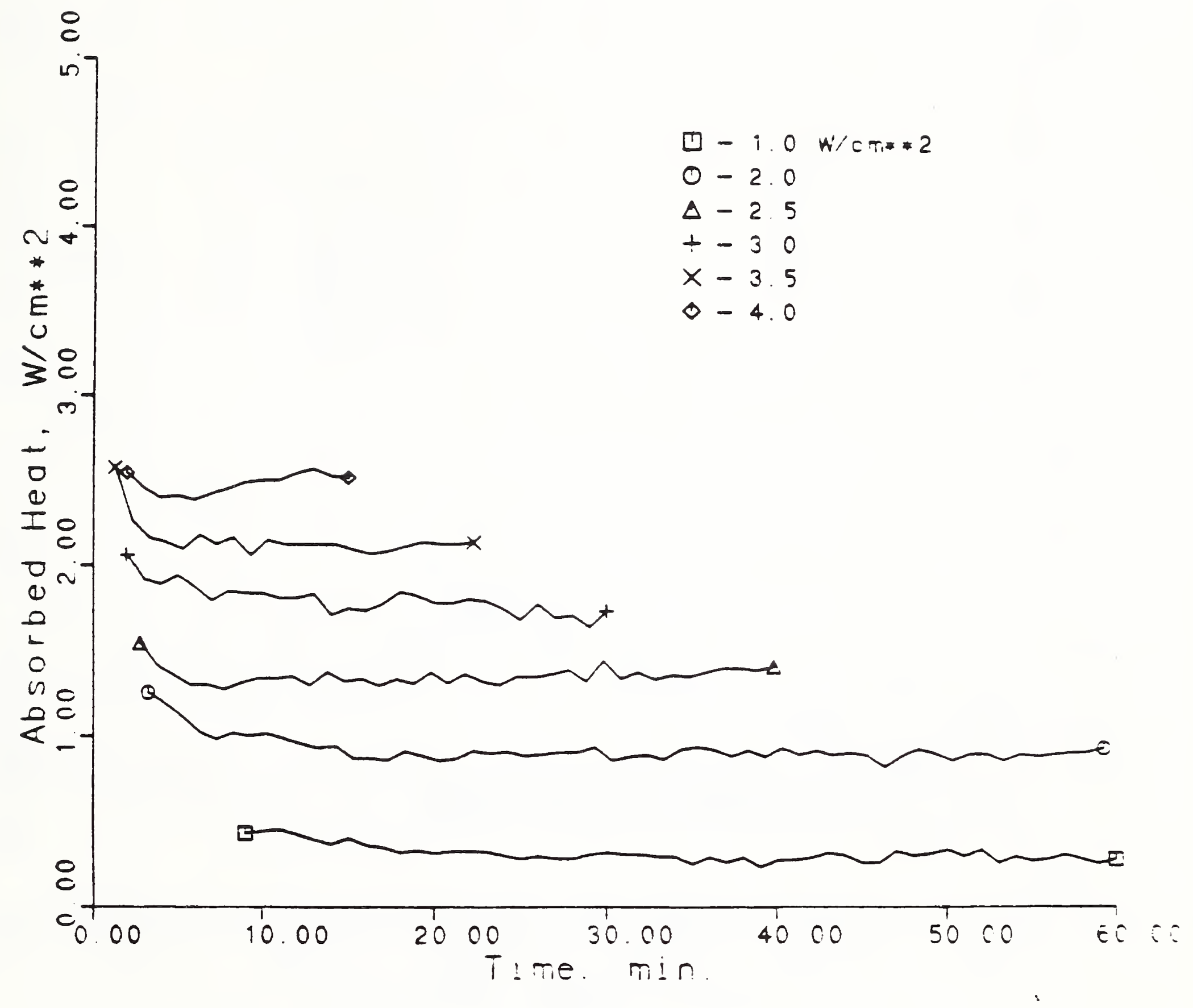

Figure 6. Absorbed heat versus time at various incident heat fluxes for PMMA. 


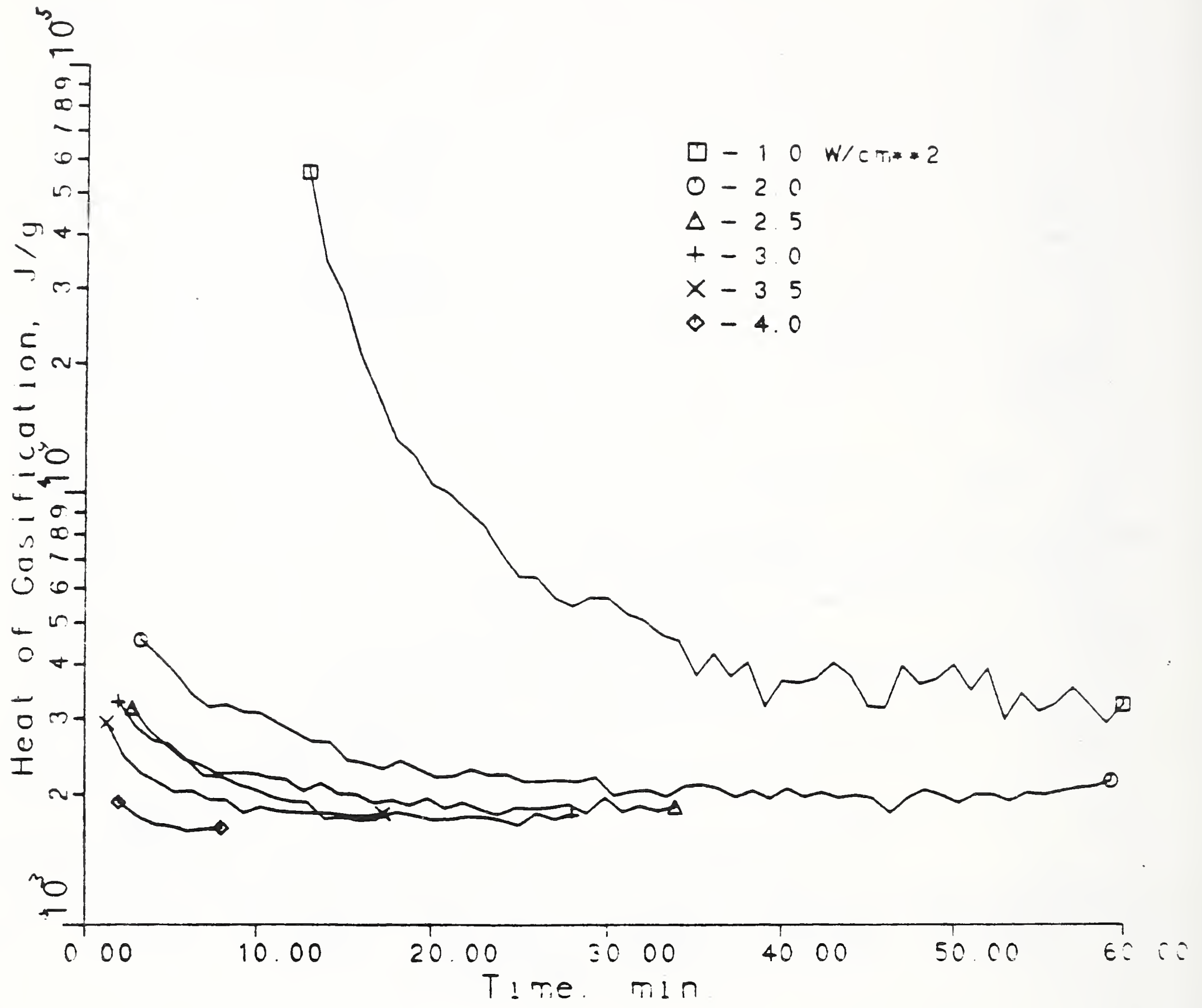

Figure 7. Heat of gasification versus time at various incident heat fluxes for PMMA. 


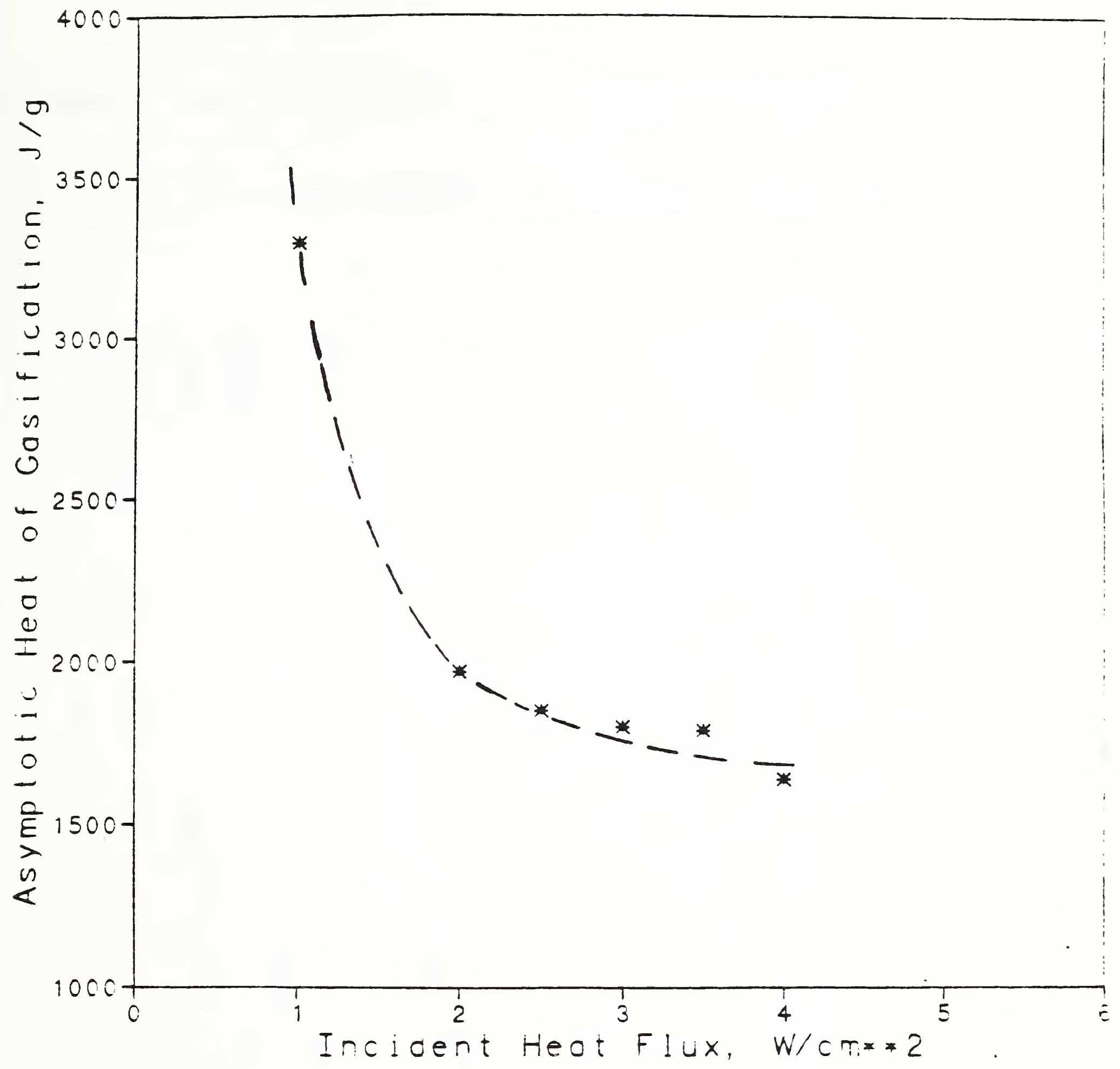

Figure 8. Asymptotic heat of gasification versus incident heat fluxes for PMMA. 
APPENDIX A

Results of Test

for Fir and Oak at Incident Heat Flux Ranges from 1 to $4 \mathrm{~W} / \mathrm{cm}^{2}$ 


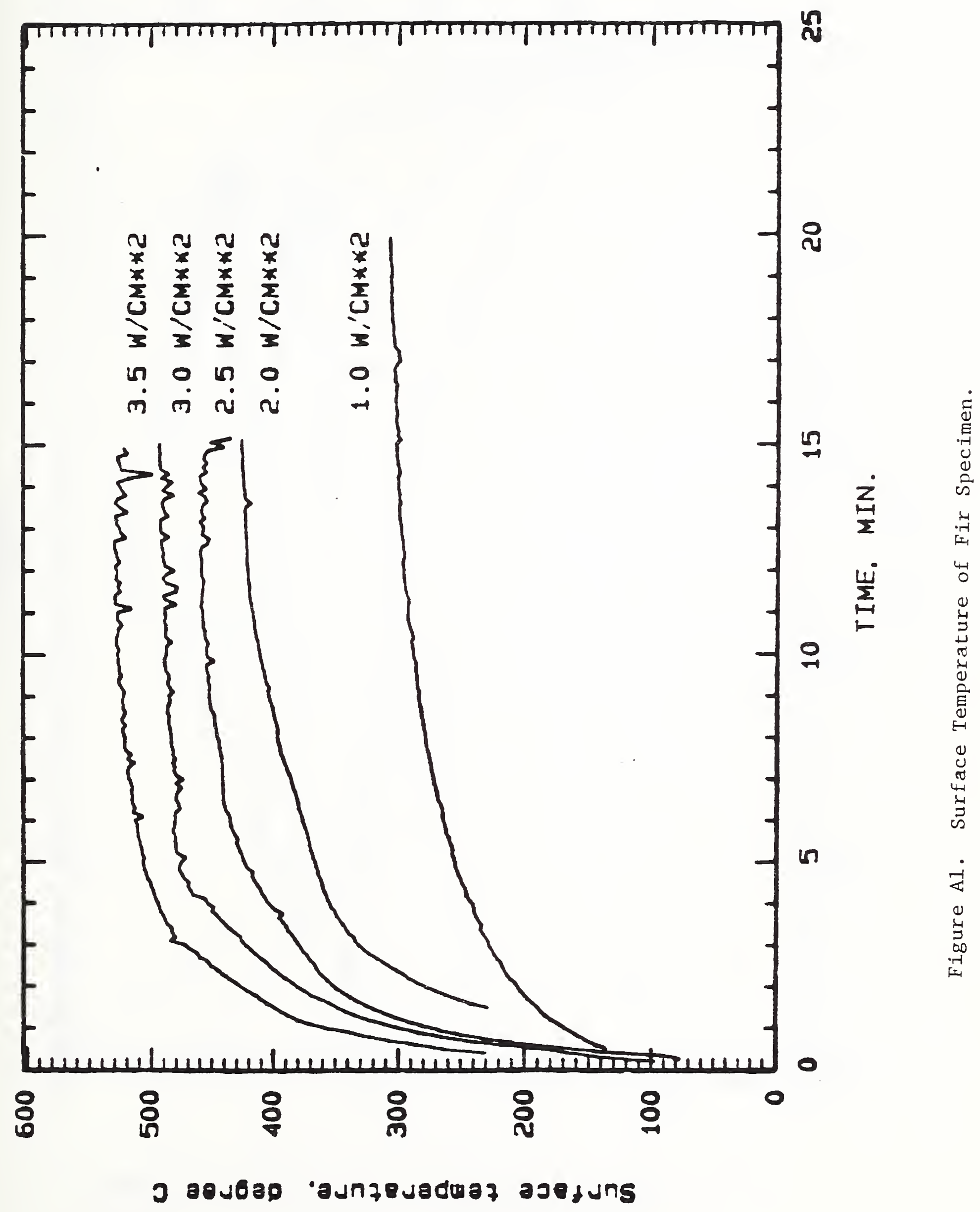


Surface temperature, degree C

管.






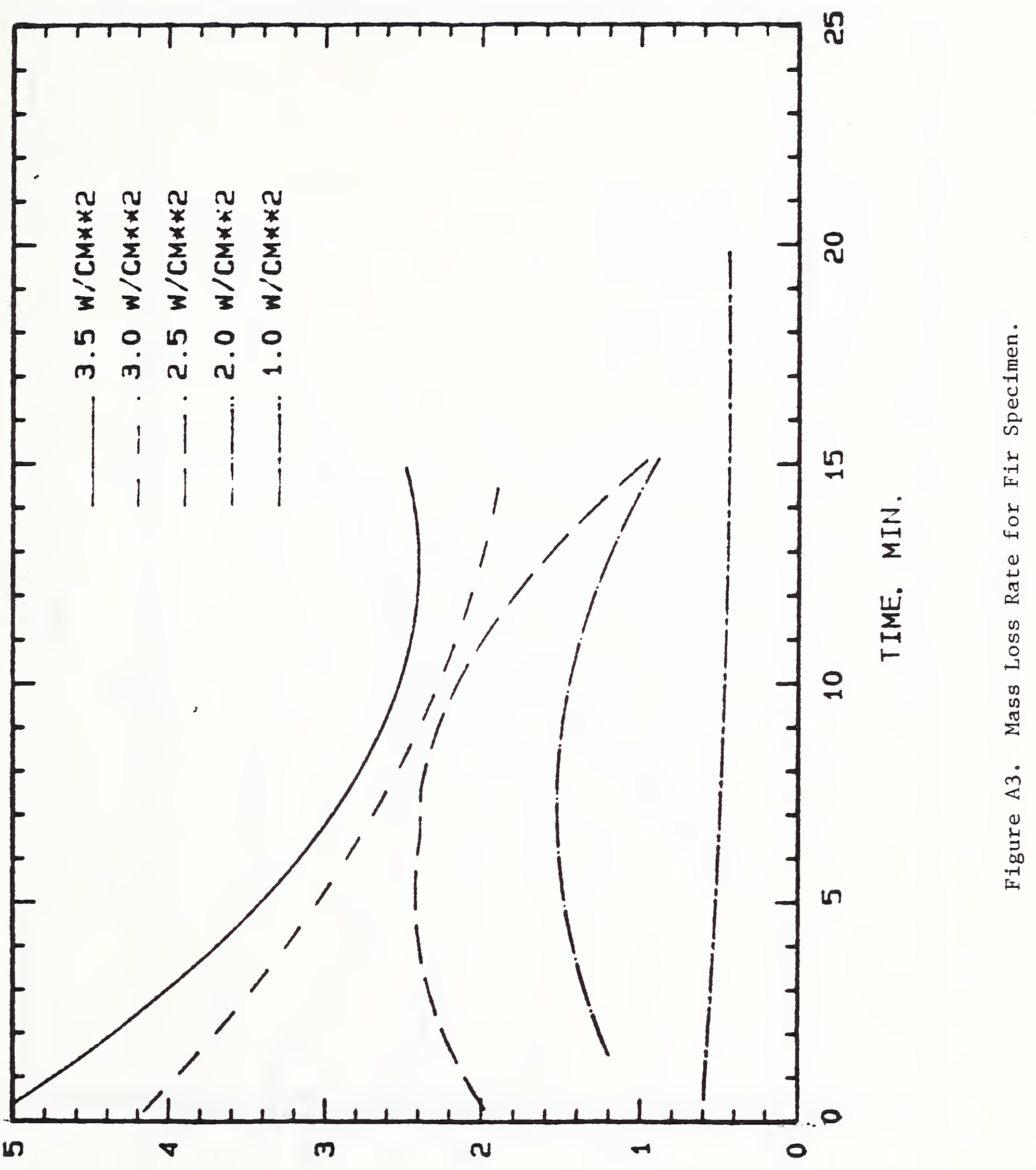

$(0 / x)$ 2**45 8/66 $27848507 \mathrm{ssew}$ 


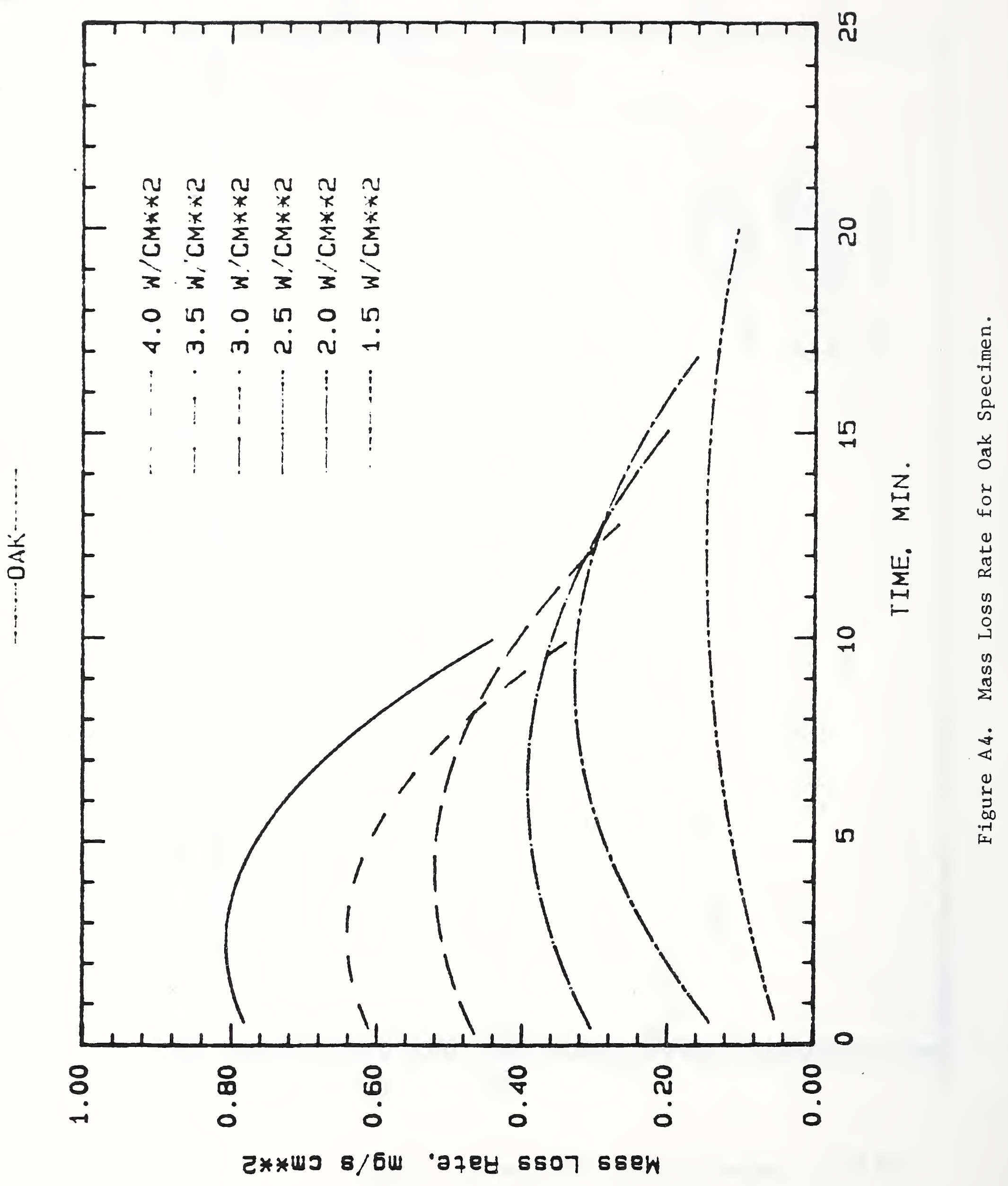




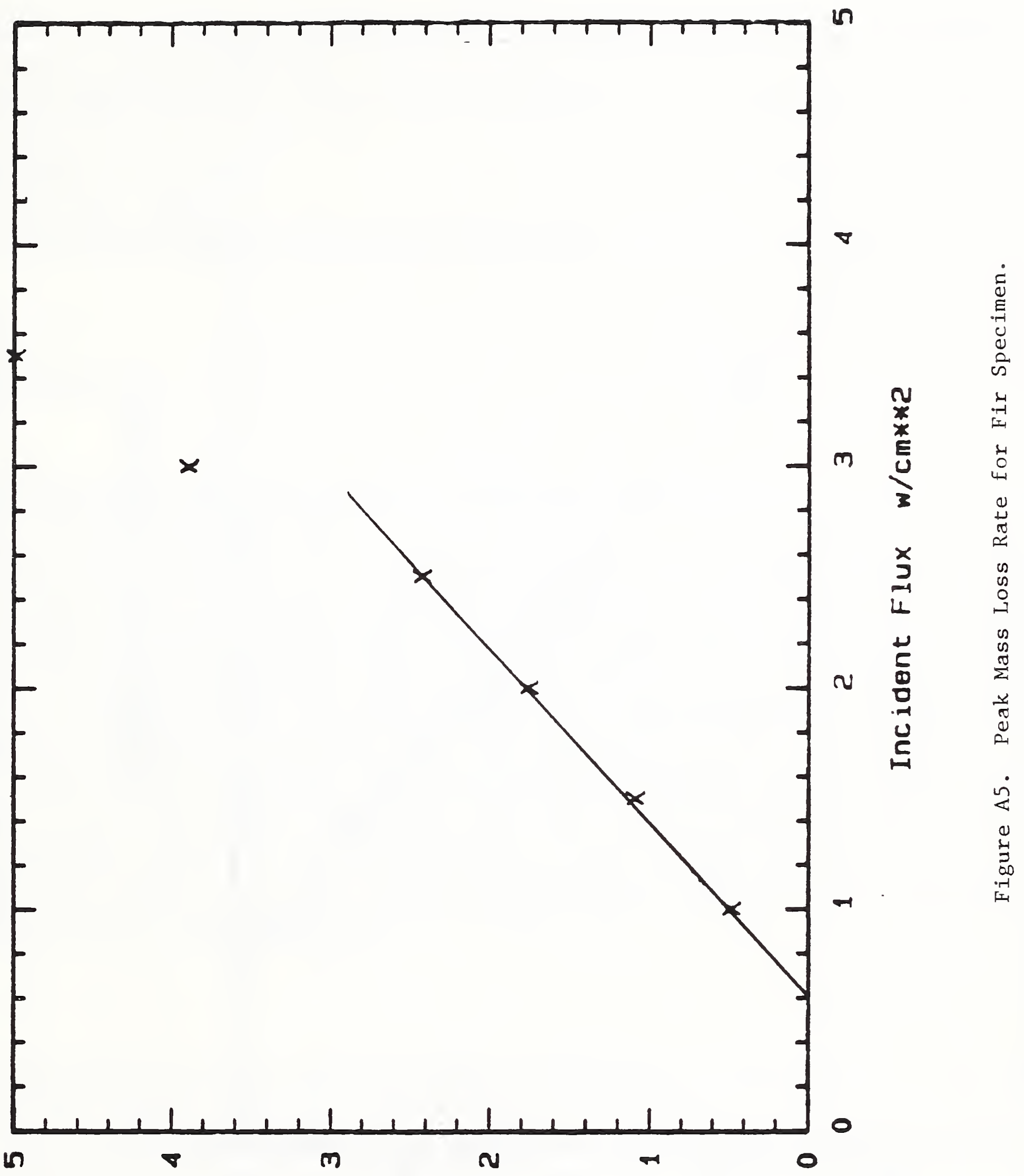

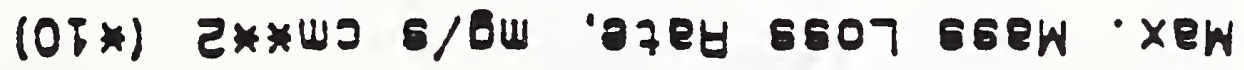




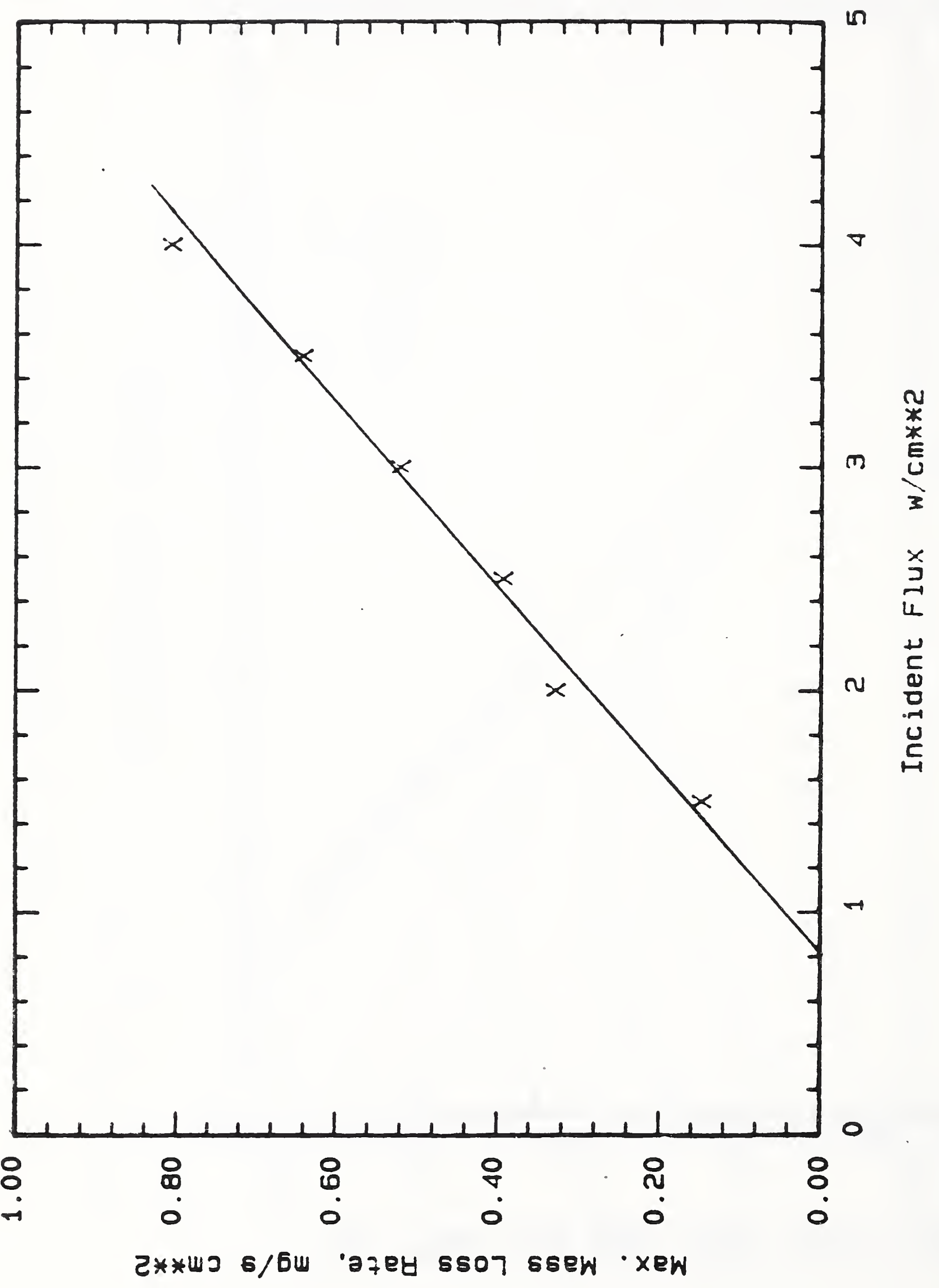

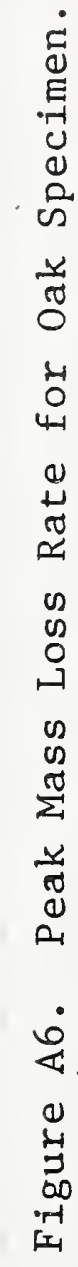


U.S. DEPT. OF COMM.

BIBLIOGRAPHIC DATA

SHEET (See instructions)

TITLE AND SUBTITLE

Direct Measurement of Heat of Gasification for Polymethylmethacrylate

5. $A U T H O R(S)$

J.L. Jackson, Research Associate

\section{PERFORMING $\cap R G A N I Z A T I O N$ (If joint or other than NBS, see instructions)}

National Institute of Standards and

Technology

U.S. Department of Commerce

Gaithersburg, MD 20899
2. Performing Organ. Report No. 3. Publication Date

October 1988

9. SPONSORING ORGANIZATION NAME AND COMPLETE ADDRESS (Street. City, State, ZIP)

7. Contracd Grant No.

8. Type of Report \& Period Covered

10. SUPPLEMENTARY NOTES

Document describes a computer program; SF-185. FIPS Software Summary, is attached.

11. ABSTRACT I A 200-word or less factual summary of most significant information. If document includes a significant titliogrophy or literature survey. mention it here)

A laboratory scale apparatus has been developed for the direct measurement of the heat of gasification for solid fuels. The apparatus has been designed to simulate radiant energy transfer rates found under actual fire conditions and designed in such a way that the energy gains and losses with respect to the sample surfaces are well defined. Calculation of the time dependent heat of gasification for solid fuels relies on the ability to measure accurately and continuously the time dependent energy transfer rates and material responses. Tests have been conducted in which samples of polymethylmethacrylate were subjected to incident heat fluxes ranging from 1 to $4 \mathrm{~W} / \mathrm{cm}^{2}$. Test results indicate that under these conditions the heat of gasification is significantly influenced by the time dependent thermal properties of the material and approaches an asymptotic value that varies with incident heat flux. The asymptotic values decrease with increasing incident heat flux and approach a value of $1600 \mathrm{~J} / \mathrm{g}$ which is consistent with values published by other investigators. Refinement of the apparatus and the testing of other materials is continuing. Results for two additional materials, fir and oak are included as Appendix A.

12. KEY WORDS (Six to twelve entries; alphabetical order; copitalize only proper names; and sepurate key words ty semicolons) burning rate; charring materials; gasification; polymethylmethacrylate; pyrolysis; solid fuels; thermal properties

13. AVAILABILITY

Zunlimited

For Official Distribution. Do Not Release to NTIS

Order From Superintendent of Documents, U.S. Government Printing Office. Washington. DC 20402.

X Order From National Technical Informacion Service (NTIS). Springfield, VA 22161

14. NO. OF PRINTED PAGES

38

15. Price

$\$ 11.95$ 
